\title{
EL LATINOAMERICANISMO DE JOSÉ MARTÍ
}

\author{
Alberto Saladino García*
}

RESUMEN: Uno de los aportes centrales de José Martí lo constituye, por el carácter aglutinador de sus inquietudes gnoseológicas como reivindicativas, su latinoamericanismo, el cual elevó al rango de principio y razón de su vida. Teóricamente sustanció el latinoamericanismo como libertario, lo fundamentó en la recuperación de nuestro pasado y en el riguroso conocimiento de la realidad para posibilitar la independencia mental, y respaldar la unidad de los países de la región. Su actitud humanista la evidenció al invocar el uso de los avances científicos y técnicos. Acerca de su praxis latinoamericanista deben destacarse sus acciones relacionadas con la concreción de los ideales bolivarianos, las alternativas de solución con la exploración de los avances del conocimiento y la entrega de su vida misma al servicio de la liberación.

En otras palabras resignificó el latinoamericanismo, el cual popularizó con la expresión nuestra América.

PALABRAS CLAVE: Antiimperialismo, Conocimiento, Independencia, Nuestra América.

ABSTRACT: Because of his gnoseological as well as his vindicative interests, one of the main contributions of José Martí is his latinoamericanism, which became his principle and reason to live. He embodied latinoamericanism as libertarian, and he based his theories by means of recovering our past and with strict knowledge of reality, to make mental independence possible and to back up the unity of the countries of the region. His humanistic attitude was evident as he promoted the use of scientific and technical advances. Notable on his latinoamericanist praxis are his actions to make the Bolivarian ideal come true, the solution alternatives with the exploration of knowledge advances and his devotion to the service of liberation.

In other words, he gave a new meaning to latinoamericanism, which he made popular with the expression "Our America."

KEY WORDS: Anti-imperialism, Knowledge, Independence, Our America.

* Universidad Autónoma del Estado de México (asaladi@uaemex.mx). 


\section{LIMINAR}

En el sesquicentenario del nacimiento de José Martí (1853-1995) resultó un imperativo abordar su pensamiento desde los más diversos aspectos, la mayoría de los cuales son sobre la actualidad de muchos de sus planteamientos; sin embargo, más allá de las efemérides, el valor de su obra ha resultado indiscutible, por lo que siempre es oportuno acercarse a ella por interés literario, por motivaciones gnoseológicas o por preocupaciones reivindicativas, etcétera.

De las variadas temáticas que se han destacado en el análisis de su original y enriquecedora obra escrita me parece conveniente ahora insistir en una que debe ser considerada central, por el carácter aglutinador de inquietudes tanto gnoseológicas como reivindicativas, me refiero a su latinoamericanismo, el cual elevó a rango de verdadera praxis a lo largo de su vida, y es una de las herencias que legó a quienes hemos asumido esta perspectiva como profesión y vocación intelectual.

Más aún, si sólo se revisara su acción política se encontraría que sus luchas independentistas y libertarias tienen como horizonte la América Latina toda, explicable porque apeló y erigió como sus inspiradores a próceres de la talla de Simón Bolívar, José de San Martín, Antonio Nariño, José Antonio Páez, Benito Juárez, etc. Así, refiriéndose al Libertador suscribe:

[...] entró ya la América en aquella hora de alma eficaz y común en que se cumplirá por fin el angustioso anhelo, el deseo profético y mortal, de aquel cuyo nombre no se ha de decir, porque con evocarlo sólo ya las almas se subliman y elevan; del que por las astas tomó a la naturaleza, cuando la naturaleza se le oponía, y la volcó en tierra; del que cuando pensó en "poner una piedra fundamental para la libertad" en América no la pidió para la libertad de Venezuela, sino para la libertad sudamericana; del que murió del afán devorador de alzar a tiempo, con un siglo de tiempo, las energías que al cabo de él habría de necesitar para su salvación, en la batalla esencial y evitable, el continente que se sacó de las entrañas. ${ }^{1}$

1 José Martí, "Discurso sobre Venezuela", en Politica de nuestra América, México, Siglo XXI, 1999, p. 100. 
De modo que José Martí, con su producción literaria y sus compromisos políticos, de manera teórica y práctica, elevó a rango de principio el latinoamericanismo al concebirlo como libertario, fundamentarlo en la recuperación de nuestro pasado y en el riguroso conocimiento de la realidad para formar gobernantes mejor preparados, que atendieran las exigencias de nuestras sociedades y para posibilitar la independencia mental, al propugnar la unidad de los países de la región y la importancia de los avances científicos y técnicos como el mecanismo más eficaz de lucha contra las diversas manifestaciones del imperialismo, con lo que exhibe una profunda actitud humanista. Así la revisión del latinoamericanismo en la obra de José Martí permite encomiar el valor de sus producciones y de su vida, pues nada más y nada menos coadyuvó a resignificar con ello la expresión América.

Resulta pertinente señalar que la original perspectiva desarrollada sobre su latinoamericanismo fue producto tanto de su agudeza intelectual, por nutrirse de las más variadas lecturas que lo adentraron en el conocimiento de la historia de nuestros países, como de sus vivencias que recogió sobre la realidad de las sociedades donde radicó, en periodos intermitentes, particularmente de México, Guatemala, Venezuela, Santo Domingo, Jamaica. En sus estancias aprendió, enseñó y divulgó datos, informaciones, interpretaciones y reflexiones sobre una amplia gama de tópicos, pues se desempeñó como periodista, profesor y editor.

Para visualizar los distintos aspectos que, desde mi perspectiva, fundamentan su concepción y praxis del latinoamericanismo, los presentaré con base en dos ejes articuladores, primero los de carácter teórico y segundo, los de carácter práctico. Ciertamente, la disociación de rasgos la amparo en el criterio pedagógico, pues debo advertir que, en estricto sentido, ese conjunto de aspectos están estrechamente vinculados, casi inseparables, entre obra y vida, y necesariamente son complementarios. 


\section{RASGOS DEL LATINOAMERICANISMO}

\section{Expresiones teóricas}

Sobre los "rasgos teóricos del latinoamericanismo" del siglo XIX codificados por José Martí, mediante los cuales expresará, sintetizará y promoverá las ideas de la centuria y la sociedad en que vivió, han de ser tomados como la oposición libertaria tanto al panlatinismo contenido en la designación francesa de Latinoamérica a nuestros territorios, concebida en 1836 por Michel Chevalier ${ }^{2}$ y conceptuada en la década de 1860 por el abad Demenech, ${ }^{3}$ como al panamericanismo que guiaba el destino norteamericano para plantar su hegemonía continental a partir de la doctrina Monroe. Latinoamericanismo que nuestro prócer va a sustanciar desde una posición preclara como se detalla a continuación, según mi particular interpretación.

\section{De vocación libertaria}

Para el independentista José Martí su vocación latinoamericana es confesa y se encuentra diseminada en muchos de sus escritos. Así en la carta dirigida a Valerio Pujol, director del periódico El Progreso de Guatemala, se evidencia su compromiso por completar la Independencia de nuestros países al explicar:

El alma de Bolívar nos alienta; el pensamiento americano me transporta. Me irrita que no se ande pronto. Temo que no se quiera llegar. Rencillas personales, fronteras imposibles, mezquinas divisiones[...] ¿qué falta podrá echarme en cara mi gran madre América? ¡Para ella trabajo! De ella espero mi aplauso o mi censura. ${ }^{4}$

2 Arturo Ardao, "Panamericanismo y latinoamericanismo", en Leopoldo Zea [coord.], América Latina en sus ideas, $3^{\mathrm{a}}$ ed., México, Siglo XXI, 2000, pp. 160-161.

3 John L. Phelan, "El origen de la idea de América", en Latinoamérica. Cuadernos de Cultura Latinoamericana, núm. 31, México, UNAM-FFyL/UDUAL, 1979, p. 19.

4 Martí, op. cit., p. 54. 
De modo que erige al Libertador en paradigma y fuente de inspiración; nuestra producción intelectual en instrumento; reconoce los múltiples obstáculos y retos, pero sobre todo clarifica su vocación y compromiso emancipatorio de la "gran madre América", esto es de todos los países ubicados al sur del Río Bravo.

Sin arredrar sacrificios, a lo largo de su vida, dio testimonios varios de su mística y entrega a tan noble causa americanista. Así, como verdadera confidencia de su heroísmo, le escribió a su amigo mexicano Manuel Mercado el 18 de mayo de 1895:

[...]ya puedo decirle con qué ternura y agradecimiento y respeto lo quiero[...] ya estoy todos los días en peligro de dar mi vida por mi país, y por mi deber - puesto que lo entiendo y tengo ánimos con que realizarlo- de impedir a tiempo con la independencia de Cuba que se extiendan por las Antillas los Estados Unidos y caigan, con esa fuerza más sobre nuestras tierras de América. Cuanto hice hasta hoy, y haré, es para eso[...]. ${ }^{5}$

Consecuentemente su pasión emancipatoria por Cuba, como todo un visionario, lo era por América Latina también.

Entonces su pensamiento expresa y tiene como norte el espíritu latinoamericano, de ahí que se planteara como razón de su vida colaborar en la liberación del total de los países de Latinoamérica. De hecho, a partir de José Martí el latinoamericanismo, como concepción teórica, le es inherente su orientación liberacionista. Para comprenderlo, desde los planteamientos de nuestro prócer, resulta pertinente ampararlo en el indispensable conocimiento del pasado.

De total inspiración histórica

Para José Martí es imperioso conocer y propalar el pasado de los pueblos latinoamericanos con el propósito de extraer enseñanzas. Su apreciación

$5 \quad$ Ibid., p. 321. 
positiva por el conocimiento pretérito le sirvió de base para explicar la necesidad de alcanzar una mejor comprensión del legado de la humanidad y de nuestras sociedades, de modo que concibió a la historia como verdadera maestra de la vida, al estilo de Cicerón.

Sus aportes al respecto y la pertinencia de divulgarlos y transmitirlos a la niñez, en particular, los sintetizan varios de los textos que componen La edad de oro. En efecto, el conocimiento histórico lo elevó a la categoría de principal herramienta intelectual para forjar identidad y cultivar valores humanistas en los seres humanos a partir de la infancia, la edad de oro de hombres y mujeres.

De las múltiples referencias históricas que hace en sus escritos, son dignas de destacar las relacionadas con la época prehispánica. Para demostrarlo transcribo in extenso sus propias palabras:

No habría poema más triste y hermoso que el que se puede sacar de la historia americana. No se puede leer sin ternura, y sin ver como flores y plumas por el aire, uno de esos buenos libros viejos forrados de pergamino, que hablan de la América de los indios, de sus ciudades y de sus fiestas, del mérito de sus artes y de la gracia de sus costumbres. Unos vivían aislados y sencillos, sin vestidos y sin necesidades, como pueblos acabados de nacer; y empezaban a pintar sus figuras extrañas en las rocas de la orilla de los ríos, donde es más solo el bosque, y el hombre piensa más en las maravillas del mundo. Otros eran pueblos de más edad, y vivían en tribus, en aldeas de cañas o de adobes, comiendo lo que cazaban y pescaban, y peleando con sus vecinos. Otros eran ya pueblos hechos, con ciudades de ciento cuarenta mil casas, y palacios adornados de pinturas de oro, y gran comercio en las calles $\mathrm{y}$ en las plazas, y templos de mármol con estatuas gigantescas de sus dioses. Sus obras no se parecen a los de los demás pueblos, sino como se parece un hombre a otro[...] Todo lo suyo es interesante, atrevido, nuevo. Fue una raza artística, inteligente y limpia. Se leen como una novela las historias de los nahuatles y mayas de México, de los chibchas de Colombia, de los cumanagotos de Venezuela, de los quechuas del Perú, de los aimaraes de Bolivia, de los charrúas del Uruguay, de los araucanos de Chile. ${ }^{6}$

6 José Martí, La edad de oro, $5^{\text {a }}$ ed., La Habana, Editorial Gente Nueva, 1999, pp. 113114. 
El relato, tan poético de la condición de los pueblos prehispánicos, que hace Martí expresa doble intención: el afán didáctico por mostrar sus distintos tipos de desarrollo y la preocupación por forjar conciencia histórica con base en informaciones orientadas a visualizar sus creaciones.

Incluso su apreciación acerca de la degeneración de esas sociedades las explicará como producto de las situaciones prohijadas por la época de la Colonia, las cuales se continúan viviendo en el periodo republicano; ${ }^{7}$ de manera que la persistencia del coloniaje es lo que impide recuperar la creatividad y así contribuir al apogeo latinoamericano. Consecuentemente, sustenta como imperativo superar las situaciones de opresión de los países latinoamericanos. Por ende, el latinoamericanismo libertario de José Martí extrae del conocimiento del pasado su principal fuente de inspiración.

De honda preocupación por el fomento del conocimiento de nuestra realidad

Pero el latinoamericanismo de José Martí, para ser libertario, exige, además del dominio de nuestra historia, el cultivo y profundización del conocimiento del presente de la realidad de los países del continente. Por ello invocará casi permanentemente la renovación educativa, ámbito específico para fomentar y generar las más diversas lógicas explicativas sobre la situación y perspectivas de Latinoamérica, desde nuestras propias circunstancias.

De las distintas instituciones educativas existentes, principalmente reconviene a las universidades el cambio de sus perspectivas gnoseológicas al sentenciar: "La universidad europea ha de ceder a la universidad americana. La historia de América, de los incas acá ha de enseñarse al dedillo, aunque no se enseñe la de los arcontes de Grecia. Nuestra Grecia es preferible a la Grecia que no es nuestra. Nos es más necesaria". 8

7 José Martí, "Nuestra América”, en Sus mejores páginas, $3^{\mathrm{a}}$ ed., México, Porrúa, 1976 (Col. Sepan Cuántos, 141), p. 91.

8 Ibid., p. 89. 
Tal conocimiento de nuestro pasado y circunstancias explica su expresión de que somos poco afortunados hasta ahora en educación, o dicho de otra manera, que mientras no se reforme y atienda la enseñanza como mecanismo liberador persistirá: "La superstición y la ignorancia [que] hacen bárbaros a los hombres en todos los pueblos", ${ }^{9}$ de lo cual se desprende la importancia que le otorgó a la nueva educación, al erigirla en mecanismo para despertar la vocación latinoamericanista a partir del esclarecimiento de la realidad, la americana.

Más aún, vincula la labor escolar con su quehacer pedagógico a través del periodismo, como quien más aprovecha la tribuna escrita para sensibilizar sobre la situación opresiva que ha acompañado la marcha de las sociedades latinoamericanas a raíz del descubrimiento y la conquista, pero también para dar a conocer la labor de los prohombres, quienes han contribuido a la búsqueda de la libertad y la justicia, como lo prueba, por ejemplo, la semblanza que hizo de Bartolomé de las Casas.

Con su maestría literaria presenta al fraile en el momento que redactaba su magna obra:

Cuatrocientos años hace que vivió el Padre las Casas, y parece que está vivo todavía, porque fue bueno[...] dicen que era hermoso verlo escribir, con su túnica blanca, sentado en su sillón de tachuelas, peleando con la pluma de ave porque no escribía de prisa. Y otras veces se levantaba del sillón, como si le quemase: se apretaba las sienes con las dos manos, andaba a pasos grandes por la celda, y parecía como si tuviera un gran dolor. Era que estaba escribiendo, en su libro famoso de la Destrucción de las Indias, los horrores que vio en las Américas cuando vino de España la gente a la conquista. Se le encendían los ojos, y se volvía a sentar, de codos en la mesa, con la cara llena de lágrimas. Así pasó la vida, defendiendo a los indios. $^{10}$

Además relata otras faenas de Las Casas a favor de los habitantes originarios de América sustentadas en su gran habilidad de usar sus

9 Martí, Política de nuestra América..., p. 80.

10 Martí, La edad de oro..., p. 193. 
conocimientos y aprendizajes para el efecto. Por ende, el fomento de la comprensión de nuestra realidad con testimonios acerca de las múltiples acciones libertarias lo llevaron a destacar el modus operandi de Bartolomé de Las Casas:

O hablaba, o escribía, sin descanso. Los frailes dominicanos lo ayudaban, y en el convento de los frailes se estuvo ocho años, escribiendo. Sabía religión y leyes, y autores latinos, que era cuanto en su tiempo se aprendía; pero todo lo usaba hábilmente para defender el derecho del hombre a la libertad, y el deber de los gobernantes de respetárselo. ${ }^{11}$

Con este testimonio José Martí establece la impronta del conocimiento tanto del pasado como del presente, como aspectos complementarios para comprender, conocer y explicar la realidad latinoamericana.

Para propugnar la independencia mental

Como todos los libertadores y muchos de los pensadores latinoamericanos, José Martí tuvo siempre presente que la práctica de la libertad sólo estará garantizada con la concreción de la independencia mental, por lo cual insistió en su preocupación por el conocimiento riguroso de la realidad latinoamericana para superar todo encubrimiento y simulación, al esclarecer: "Éramos una máscara, con los calzones de Inglaterra, el chaleco parisiense, el chaquetón de Norte América y la montera de España". ${ }^{12}$ Así, para él resulta una urgencia trascender ese retrato del siglo XIX sobre el comportamiento de las oligarquías latinoamericanas, mediante una educación que atienda primordialmente los asuntos propios, los vinculados con la solución de la problemática existente.

Ciertamente el particularismo que se trasluce en varios de sus planteamientos no puede significar la exclusión del conocimiento de otras

${ }^{11}$ Ibid., p. 200.

12 Martí, Sus mejores páginas..., p. 91. 
manifestaciones de la realidad, más bien propone el sugerente enfoque de conocer el mundo desde nuestra perspectiva, la de carácter latinoamericana para así insertar a nuestros países en el mundo, de modo que se comprenda que: "El problema de la independencia no era el cambio de formas, sino el cambio de espíritu". ${ }^{13}$

Mediante esta problematización, volvemos a encontrar la genuina inspiración martiana del latinoamericanismo, esto es, la idea de superar todo doblez, farsa o simulación a partir del conocimiento de nosotros mismos como condición para acceder a la práctica de la libertad.

Para respaldar esa visión, José Martí apela por una educación racional, que enseñe el uso de los adelantos científicos y técnicos al otorgarles amplios reconocimientos con el propósito de internalizarlos en la cultura latinoamericana por lo que plantea: "La grandeza de los pueblos no depende acaso sino de aceptar al mismo tiempo y sin demora, todo lo útil: y en educar racionalmente a los niños". ${ }^{14}$

En los planteamientos y propuestas de José Martí destaca la necesidad de sustanciar la independencia mental de los latinoamericanos con base en una educación liberadora, por racional, científica y útil, al promover el aprovechamiento de los progresos científicos y las innovaciones técnicas.

Precursor de la transferencia del know how para mejorar las condiciones de vida

Uno de los aspectos que me parece poco se ha dilucidado en la obra de José Martí lo constituye su concepción acerca de los avances científicos y técnicos. Ciertamente, la tarea empieza a ser hecha. Uno de quienes ha afrontado este reto, luego de un arduo proceso de investigación, llegó a

13 Ibid., p. 91.

${ }^{14}$ Citado por Rafael Almanza Alonso, Hombre y tecnología en José Martí, Santiago de Cuba, Editorial Oriente, 2001, p. 41. 
la conclusión de que nuestro forjador de la vocación latinoamericanista dedicó tiempo para informarse sobre estos saberes racionales y escribió varios textos donde los divulgó. La consecuencia fue haberse erigido en el promotor de sus usos para atender necesidades latinoamericanas.

Dedicado a la elaboración de un proyecto de progreso económico independiente para Latinoamérica, en el que la "transferencia tecnológica" era un elemento decisivo, Martí entendió la necesidad de enfrentar todo el avance técnico contemporáneo, en particular de las tecnologías de vanguardia, y de hacerlo conocer a todos -especialmente, a los niños. A esta titánica propaganda sirvió con su don de poeta y de pensador, abriendo el fenómeno tecnológico, sin miedo y con honesta destreza, a todos sus conmocionadores significados. Y tampoco eludió el lenguaje técnico, en aras de la información plena y leal. Revolucionario integral, de la economía y de la política, de la sociedad y del individuo, de la vida material y del espíritu. Martí tenía que asumir como tarea propia la revelación a su pueblo latinoamericano de las transformaciones radicales de la técnica de su época, que parecían llevar inscritas en su naturaleza profunda la promesa de la liberación cabal de la humanidad. ${ }^{15}$

Según se puede observar, las propuestas martianas tienen el interés de usar los avances científicos y técnicos para que los habitantes de nuestros países los usufructuen, por lo cual profundizó sus informaciones y atendió la comprensión del lenguaje especializado con el afán de popularizarlos y hacerlos asequibles.

Como hombre de su tiempo, José Martí escrutó las virtudes de los inventos del genio humano, por lo que cantó loas a sus usos en los países latinoamericanos. En uno de sus textos narró:

Los pueblos nuevos de América, que con prisa mexicana y bonaerense están determinados a subir de un salto el puesto a que su inteligencia y riqueza natural los llaman, obrarán con cordura al reemplazar el alumbrado turbio de sus calles tenebrosas, en sustituir el que está demostrando ya todas sus ventajas sobre el gas: el alumbrado eléctrico. ${ }^{16}$

${ }^{15}$ Ibid., pp. 84-85.

${ }^{16}$ Citado en ibid., p. 59. 
De modo que su vocación latinoamericana traspasó sus planteamientos políticos, toda vez que sus apreciaciones sobre los saberes racionales, los científicos y técnicos, también parecen promoverla.

Tal como se ha explicado el latinoamericanismo reactualizado por José Martí tiene diversos fundamentos, donde sus inquietudes políticas concitan planteamientos educativos, culturales, históricos, científicos y técnicos.

\section{Praxis latinoamericanista}

Además de dichos aspectos, que he venido exponiendo como teóricos, existen otros que muestran de mejor manera su mística latinoamericanista a través de su persistente actitud y compromiso por contribuir a la consecución de la Independencia de nuestros países. Ese es el caso de los "rasgos de su praxis latinoamericanista", entre cuyos aspectos pueden destacarse los planteamientos y acciones relacionados con la concreción de los ideales bolivarianos y la consideración de las nuevas exigencias de los pueblos, a los que Martí busca otorgarles alternativas de solución explorando los avances del conocimiento y entregando su vida misma al servicio de la liberación.

La promoción de la unidad de nuestros países

Martí insistirá en la necesidad de profundizar el conocimiento de la realidad de las naciones latinoamericanas. Sus palabras al respecto resultan elocuentes: "Los pueblos que no se conocen han de darse prisa para conocerse[...] Es la hora del recuento, y de la marcha unida, y hemos de andar en cuadro apretado, como la plata en las raíces de los Andes". ${ }^{17}$

${ }^{17}$ Martí, Sus mejores páginas..., p. 87. 
En consecuencia, se trata no sólo de fomentar el conocimiento puntual del pasado y de su asimilación, sino sobre todo de enraizarlo en la realidad, de aceptarla tal cual es. Sólo debe advertirse que ello no significa soslayar el eje articulador y fin último de su proceder, lo que constituye su praxis por la unidad latinoamericana.

Más aún, como he anticipado, sus convicciones libertarias las respalda en la comprensión de las luchas y expectativas de los héroes que nos dieron patria y, sobre todo, de aquellos que pugnaron por la unidad de nuestros países, a los cuales busca emular por medio de su prédica como por sus compromisos y su incansable lucha política. De ahí el permanente recuerdo que hace de los héroes latinoamericanistas como Simón Bolívar, José de San Martín, Benito Juárez, etcétera.

En efecto, consideró como fundamento de la consumación de la Independencia de todos los países latinoamericanos la concreción de su ineludible unidad continental, la cual sería, asimismo, su garantía y soporte principal para impulsar el mejoramiento del nivel de vida de sus habitantes.

Adjudica al dominio del conocimiento la responsabilidad para servir mejor

Quizá, como pocos de los políticos de Latinoamérica, el pensamiento de José Martí presenta como impronta la exigencia de que nuestros gobernantes deben contar con una formación adecuada, esto es, contar con informaciones rigurosas y exactas sobre la realidad a gobernar, por eso sustancia:

[...]el buen gobernante en América[...] es[...] el que sabe con qué elementos está hecho su país[...] El gobierno ha de nacer del país. El espíritu del gobierno ha de ser del país[...].

¿Cómo han de salir de las universidades los gobernantes, si no hay universidad en América donde se enseñe lo rudimentario del arte del gobierno, que es el análisis de los elementos peculiares de los pueblos de 
América?[...] Conocer es resolver. Conocer el país y gobernarlo conforme al conocimiento, es el único modo de librarlo de tiranías[... ${ }^{18}$

Entonces la divisa del latinoamericanismo forjado por José Martí será conocer para resolver, esto en primera instancia. Y esto lo han de asimilar los políticos porque para él gobernar es servir, verdadera esencia moral y razón de ser de la política. Más aún, el espíritu latinoamericanista de José Martí lo sintetiza su frase: "Pensar es servir", ${ }^{19}$ que los latinoamericanistas del siglo XXI debiéramos erigir en la insignia de nuestros quehaceres y afanes.

El entusiasmo que tiene por los avances de los conocimientos científicos y técnicos forma parte de la exhortación para insistir en su dominio, pues su apreciación de considerarlos benéficos es porque ayudan a enfrentar las exigencias y expectativas existentes en los pueblos latinoamericanos, motivo que lo llevó a popularizarlos. Para sustentar esta concepción me parece pertinente acudir a sus propias palabras: "Estudiar las fuerzas de la naturaleza, y aprender a manejarlas, es la manera más derecha de resolver los problemas sociales". ${ }^{20}$

Lo transcrito demuestra que José Martí tenía una idea precisa de la razón de ser y la función socioeconómica del conocimiento científico, que el siglo XIX institucionalizó y divulgó como expresión del avance del capitalismo en su fase monopolista.

Propugnó el servicio como razón del latinoamericanismo

Por sus convicciones y por las diversas condiciones de vida que padeció José Martí, pienso que pudo llevar a la práctica su latinoamericanismo tanto como periodista como por haber representado a varios gobiernos y organizaciones civiles. Téngase en cuenta que su gran obra escrita apare-

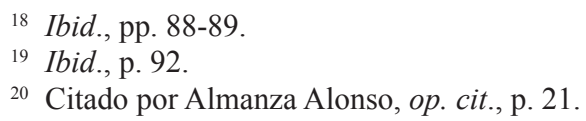


ció en más de veinte publicaciones periódicas que circularon en distintos países de Hispanoamérica, entre las cuales destacan: La Nación, de Buenos Aires; El Partido Liberal, de México; La Opinión Nacional, de Caracas; La Opinión Pública, de Montevideo, y de publicaciones de Guatemala, Honduras y, naturalmente, de Cuba.

Como pocos personajes de nuestra vida pública, José Martí fungió como representante de gobiernos y de organizaciones culturales y políticas en distintos foros. Fue cónsul de Uruguay en Nueva York (1887); representante de la Asociación de la Prensa de Buenos Aires en Estados Unidos y Canadá (1889); cónsul de Argentina y Paraguay en Nueva York (1890); representante de Uruguay en la Conferencia Monetaria Internacional Americana (1890), etc. Por ende su praxis latinoamericanista refrenda el vínculo singular de sus ideas y sus acciones.

$\mathrm{Su}$ vocación por servir y ser útil a las sociedades latinoamericanas lo llevó a nutrirse de informaciones especializadas para ponerlas al servicio de ellas, incluso llegó a suscribir argumentos donde pone en evidencia la necesaria atención que se debe tener a los avances científicos y a los inventos e innovaciones técnicas por los usos variadísimos que de ellos se pueden obtener. Por ejemplo el caso de la electricidad fue uno de los desarrollos tecnológicos del siglo XIX que mayores posibilidades de aplicación vislumbró, por lo que al respecto escribió:

El departamento en que hemos de tener puestos con más cuidado los ojos los latinoamericanos, es el de las aplicaciones de la electricidad a las minas y a la agricultura: en este departamento entrarán también los inventos aplicables a la navegación. De un lado se verán los usos de la electricidad en la medicina y en la cirugía: de otro, todos los modos de servir de la fuerza eléctrica a la meteorología, a la astronomía, y a la geodesia. ${ }^{21}$

Los planteamientos visionarios de José Martí se explican por el dominio de los conocimientos de frontera que tuvo y el reconocimiento de su importancia económica, política, social y cultural, por lo cual

${ }^{21}$ Ibid., p. 44. 
promovió darlos a conocer a las sociedades latinoamericanas por sus beneficios imprescindibles.

De innegable raíz antiimperialista

Para José Martí el latinoamericanismo es expresión de rebeldía contra el colonialismo y el neocolonialismo que amenazaba el mundo a finales del siglo XIX, por lo cual suscribió la necesidad de continuar las luchas independentistas. En sus propias palabras: "De la tiranía de España supo salvarse la América española; y ahora, después de ver con ojos judiciales los antecedentes, que ha llegado para la América española la hora de declarar su segunda independencia". ${ }^{22}$

Así las pruebas palpables de su acendrado latinoamericanismo radican en sus observaciones críticas contra el panamericanismo, el cual desentraña y esclarece como la política estadounidense de expansión sobre territorios de los países de América, por lo que explica —alerta - que tal doctrina no significa sino "[...] la era del predominio de los Estados Unidos sobre los pueblos de las Américas". ${ }^{23}$

Por todo ello, José Martí sistematiza su latinoamericanismo como la praxis de la lucha por la libertad e independencia de nuestras naciones con base en el conocimiento de sus realidades, anunciando que el desdén de Estados Unidos se debe a que no la conoce, por lo cual lanza la advertencia de que tal ignorancia constituye nuestro mayor peligro a enfrentar. ${ }^{24}$

De hecho, esta postura antiimperialista la propaló no sólo como denuncia política, sino también mediante el análisis de sucesos de coyuntura como el interés norteamericano de proyectar un canal interoceánico en Nicaragua, al afirmar:

22 Martí, Política de nuestra América..., pp. 25 y 152.

${ }^{23}$ Ibid., p. 159.

24 Martí, Sus mejores páginas..., p. 92. 
Parece como si se quisiera ganar por la mano al canal de Panamá, y obtener para los Estados Unidos las ventajas de una línea interoceánica construida por ellos, y con su dinero y garantía, sin los conflictos internacionales que traerá sin duda el ejercicio del mismo intento respecto al canal de Panamá. ${ }^{25}$

La interpretación anticipadora y esclarecedora suscrita por José Martí se entiende debido al profundo conocimiento que, como pocos, tuvo de las entrañas del imperialismo, pues vivió en su seno y así elaboró sus conceptualizaciones a partir de vivencias de primera mano.

De profunda actitud humanista

Porque José Martí muestra al latinoamericanismo como una praxis incluyente no sólo para conocernos, sino como una concepción abierta al conocimiento y comprensión del resto de la humanidad, desde la posición americana. Asimismo, su actitud humanista le permitió afrontar con brillantez uno de los problemas sociales más acuciantes de América Latina, el de la diversidad racial que entonces se tomaba como obstáculo para el desarrollo nacional, pues al respecto recuérdese la posición etnocida de los positivistas latinoamericanos como Francisco Cosmes, mexicano, y Alcides Arguedas, boliviano, por citar dos casos muy representativos.

De manera visionaria y genial muestra que las discriminaciones son de carácter social, no de tipo natural o racial como lo venían justificando los colonialistas y que en su época lo reiteraban los corifeos del positivismo, por lo cual insistía en la necesidad de superar ese tipo de interpretaciones al suscribir:

No hay odio de razas[...] en la justicia de la Naturaleza[...] resalta[...] la identidad universal del hombre. El alma emana, igual y eterna, de los cuerpos diversos en forma y en color. Peca contra la Humanidad el que fomente y propague la oposición y el odio de las razas[...]. ${ }^{26}$

${ }_{25}$ Citado por Almanza Alonso, op. cit., pp. 119-120.

${ }^{26}$ Martí, Sus mejores páginas..., p. 92. 
Esa actitud crítica, racional y liberacionista propalada por el prócer cubano trasciende, incluso, los tradicionales planteamientos para combatir la discriminación, puesto que apela al progreso y desenvolvimiento de las sociedades con base en el aprovechamiento de los avances del conocimiento científico, y de las innovaciones tecnológicas, al grado de que se ha interpretado que:

[...] lo que Martí propone a Latinoamérica en materia de progreso tecnológico no es sólo un arma contra las supervivencias feudales y por un capitalismo independiente y democrático, sino sobre todo ese "reinado del hombre", esa época de la "verdadera revelación [...] del hombre a sí propio" a la que insistentemente se refirió en estos textos de principios de los ochenta. ${ }^{27}$

\section{RESEMANTIZACIÓN DE AMÉRICA}

En efecto, José Martí con el uso del término América en combinación con otras palabras lo resemantizó al acotar su empleo para identificar a los pueblos y sociedades ubicadas al sur del Río Bravo. Pero esta labor filológica sólo resulta explícita si se le contextualiza como parte de los nobles propósitos de su quehacer libertario en beneficio de nuestros países a los que aglutina en las expresiones "nuestra América", "madre América", "nuestra América fabulosa" - como indistintamente la 1lamó- pues fue tanto su fin como razón de su existencia, llegando incluso al grado de poetizar sus inquietudes cuando reconoce:

[...] ipero a Venezuela[...] que como toda nuestra América, a nuestra América desinteresada, la hemos de querer y de admirar sin límites, porque la sangre que dio por conquistar la libertad ha continuado dándola por conservarla! ¡Proclamemos, contra lacayos y pedantes, la gloria de los que en la gran labor de América se van poniendo de quicio y abono para la paz libre y decorosa del continente y la felicidad e independencia de las generaciones futuras! ${ }^{28}$

27 Almanza Alonso, op. cit., p. 25.

28 Martí, Política de nuestra América..., p. 98. 
Para abonar esa loa debe añadirse su posición encomiable sobre el significado de la llegada de los europeos a nuestro continente al decir: "El descubrimiento de América rehizo el mundo, sacudió sus cimientos viejos, le envió, a refrescarle los pulmones cansados, aires nuevos, amplió y reformó el comercio, puso en la mano del hombre las riendas de sí mismo". ${ }^{29}$

La consecuencia de esa labor de semantización es lo que permite sustentar que José Martí otorgó nuevas bases al latinoamericanismo emancipador del siglo XIX, lo nutrió de elementos científicos, culturales, económicos, educativos, políticos y sociales, con el propósito de diferenciarlo y, a la vez, para oponerlo al panlatinismo y al panamericanismo.

La claridad meridiana de sus convicciones las reitera en diversos pasajes de sus escritos, por lo que abuso de una última cita para dejar constancia de su vocación latinoamericanista: "De América soy hijo; a ella me debo. Y de la América, a cuya revelación, sacudimiento y fundación urgente me consagro". ${ }^{30}$ Su biografía es la mejor prueba y respaldo de su praxis al respecto.

En fin, la obra de José Martí, en general, y de su latinoamericanismo, en particular, representa la contribución más elocuente del pensamiento latinoamericano del siglo XIX a la comprensión de nuestra realidad americana y del mundo desde una nueva óptica, la descolonizada.

29 Citado por Almanza Alonso, op. cit., p. 40.

${ }^{30}$ Martí, Política de nuestra América..., p. 58. 